\title{
Influence Analysis of Cracks of the Sluice Bottom Board
}

\author{
Jianhua Cui ${ }^{1, a}$, Jiajun Yan ${ }^{2, b}$, Yongfeng $Q i^{1, c}$ \\ ${ }^{1}$ Changjiang River Scientific Research Institute, Wuhan 430010, China \\ ${ }^{2}$ Changjiang Institute of Survey, Planning, Design and Research, Wuhan 430010, China \\ acuijh@mail.crsri.cn, ${ }^{b} 531330186 @ q q . c o m,{ }^{c}$ Qiyf@mail.crsri.cn
}

Keywords: Sluice, Bottom Board, Crack, 3D-FEM

\begin{abstract}
After running for half a year, periodic inspection to a discharge sluice shows that cracks in the direction of water current appear in the bottom board of most of sluice lockage chamber. Stress computation under the design conditions and the working conditions after cracks appeared are carried out with 3D-FEM respectively. The results indicated that the stress of the bottom board is still within the allowed range, the structure is safe from the view of the stress. But considering the defective parts of bottom surface and interlayer surface are likely to be connected with vertical cracks, seepage follow channel will be formed, and it will affect the long-term safe operation of the whole structure, it is suggested that cracks in bottom board should be repaired.
\end{abstract}

\section{Introduction}

After running for half a year, periodic inspection to a discharge sluice shows that cracks in the direction of water current appear in bottom board of most of the drainage holes (see Fig.1), and white slurry separate out from some cracks. According to the literature [1,2,3], cracks are commonly found in bottom board of the sluice. Once the deep cracks or through cracks appear, it will change the load conditions of the structure, and affect the integrity of the structure.

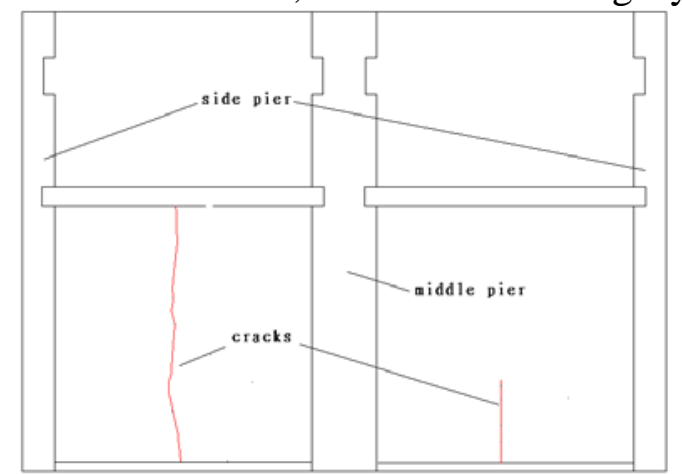

Fig.1 cracks in bottom board of a sluice lockage chamber

The cracks may cause steel corrosion,reduce the durability of the structure, and shorten the service life of the project. So it is necessary to make further research on the sluice structure with cracks, and analyze the effect of cracks on the load conditions of the sluice structure.

In this paper, taking some typical sluice chamber section as the research object, stress computation under the design conditions and the working conditions after cracks appeared are carried out with 3D-FEM [4] respectively, and sensitivity analysis of various factors for the sluice structure are performed. The results will give scientific references for the crack treatment.

\section{Computation model}

Figure 2 is used for the calculation of gravity condition. Considering the casting process of each section may be not synchronous, we take three section and part of the lower basis as the research object, and extend the simulation range of the foundation to a certain range in the axial direction. The model contains 86028 elements and 102628 nodes. Figure 3 is used for the calculation of 
operating conditions. Considering the symmetry of the structure and the loads, we take a single section and the lower basis as the research object. The model contains 53388 elements and 62046 nodes. Concrete, foundation and steel bar are considered in the calculation, and the main loads include gravity, vertical load on the top of the structure, water pressure and uplift pressure etc.

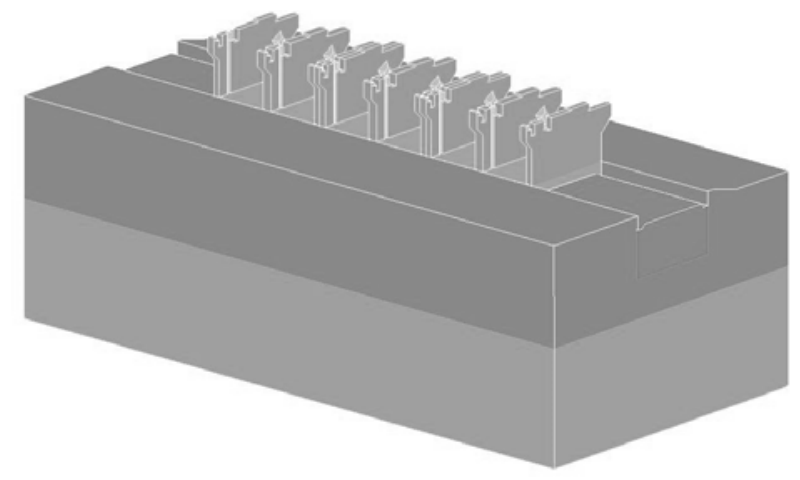

Fig.2 Calculation model (three section)

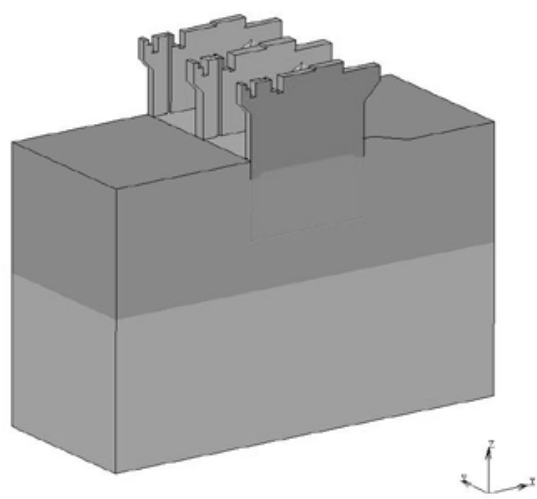

Fig.3 Calculation model (one section)

\section{Structure stress under design conditions}

\section{Influence of the foundation simulation range to the structure stress (for gravity condition)}

To analyze the influence of the foundation simulation range, we consider the distance between the constraint of the foundation and the edge pier as $0.0 \mathrm{~m}, 0.5 \mathrm{~m}, 3.4 \mathrm{~m}, 10.2 \mathrm{~m}, 17.0 \mathrm{~m}, 34.0 \mathrm{~m}$, $51.0 \mathrm{~m}$ respectively. The maximum axial stress under different foundation simulation ranges are shown in Table 1 . We can see that when the distance is above $10.2 \mathrm{~m}$, the calculation results are basically stable.

Tab.1 The maximum axial stress of bottom board

\begin{tabular}{cccc}
\hline Scheme & $\begin{array}{c}\text { the distance between the } \\
\text { constraint of the foundation } \\
\text { and the edge pier(m) }\end{array}$ & $\begin{array}{c}\text { Stress of upstream } \\
\text { side(MPa) }\end{array}$ & $\begin{array}{c}\text { Stress of downstream } \\
\text { side(MPa) }\end{array}$ \\
\hline 1 & 0 & 1.58 & 1.85 \\
2 & 0.5 & 1.93 & 2.19 \\
3 & 3.4 & 2.07 & 2.32 \\
4 & 10.2 & 2.20 & 2.43 \\
5 & 17.0 & 2.24 & 2.46 \\
6 & 34.0 & 2.23 & 2.46 \\
7 & 51.0 & 2.22 & 2.44 \\
\hline
\end{tabular}

\section{Stress of sluice bottom board under gravity condition}

Stress contour of bottom board of sluice is shown in Figure 4. When the structure jointing is free, the maximum stress appears in the middle part of sluice hole, the values of upstream side and downstream side is $2.23 \mathrm{MPa}, 2.46 \mathrm{MPa}$ respectively. When the structure joint is considered with contact, the corresponding maximum stress is $1.55 \mathrm{MPa}, 1.79 \mathrm{MPa}$, the maximum stress are obviously reduced. The main reason is when the structure jointing is considered with contact, the free deformation of the chamber section is limited, so the maximum stress is reduced. 


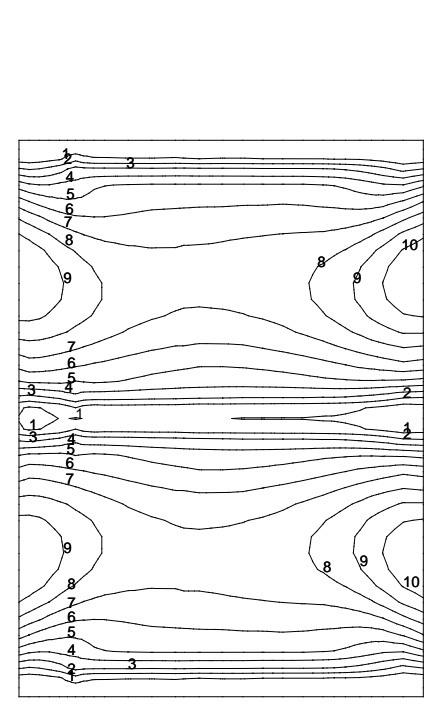

(The structure joint is free)

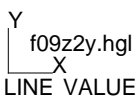

L $\quad-.020$

$1 \quad .205$

2.431

$3 \quad .656$

$4 \quad .882$

$5 \quad 1.107$

$6 \quad 1.333$

$7 \quad 1.558$

$8 \quad 1.784$

$9 \quad 2.009$

$10 \quad 2.235$

H 2.460
Y f18z2y.hgl
LINE VALUE

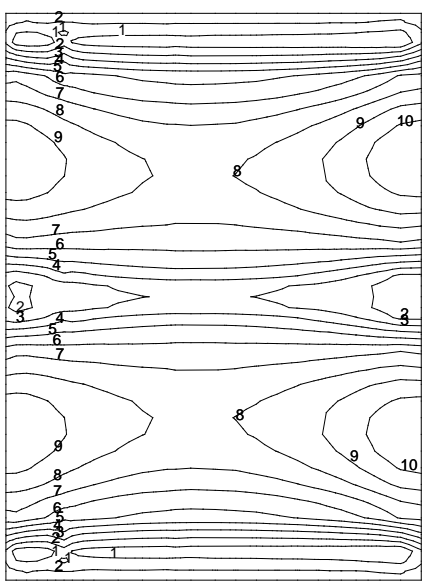

$L \quad-.530$

$1 \quad-.319$

$2 \quad-.108$

$3 \quad .103$

$4 \quad .314$

$5 \quad .525$

$6 \quad .735$

$7 \quad .946$

$8 \quad 1.157$

$9 \quad 1.368$

$10 \quad 1.579$

H 1.790

Fig.4 The stress distribution of the top surface of the bottom board (MPa)

\section{The stress of the sluice under normal operation condition}

The stress in the flow direction and vertical direction are all small, while the stress across the flow direction is bigger, which located in the middle part of the sluice hole. When considering the wood interlayer between two sluice chamber sections, the maximum axial tensile stress on upstream side and downstream side of the bottom board are $0.89 \mathrm{MPa}, 1.21 \mathrm{MPa}$ respectively. When the side piers are free, the corresponding data are 1.81MPa, 2.34MPa. Restraint mode of the side pier has a great influence on the stress of the bottom board. Considering the actual situation of engineering, it is more suitable to take the wood interlayer between two sluice sections into account.

\section{Effect analysis of cracks to the structure}

\section{Main results}

The maximum axial stress of the bottom board, the maximum steel stress and the opening of vertical cracks are shown in table 2. Point A and Point B are located on the upstream side and downstream side of the top surface of the bottom board respectively.

Tab.2 Main Calculation Results

\begin{tabular}{ccccccc}
\hline Scheme & $\begin{array}{c}\text { The depths } \\
\text { of cracks(m) }\end{array}$ & $\begin{array}{c}\text { Steel } \\
\text { bar }\end{array}$ & $\begin{array}{c}\text { Stress of Point } \\
\text { A (MPa) }\end{array}$ & $\begin{array}{c}\text { Stress of Point } \\
\text { B (MPa) }\end{array}$ & $\begin{array}{c}\text { Stress of steel } \\
\text { bar (MPa) }\end{array}$ & $\begin{array}{c}\text { Opening of } \\
\text { the crack (mm) }\end{array}$ \\
\hline 1 & - & - & 0.89 & 1.21 & - & - \\
2 & - & $\sqrt{ }$ & 0.76 & 1.11 & 7.5 & - \\
3 & 2.5 & - & 0.23 & 0.35 & - & 0.79 \\
4 & 2.5 & $\sqrt{ }$ & 1.32 & 1.67 & 91.5 & 0.15 \\
5 & 1.5 & $\sqrt{ }$ & 1.20 & 1.44 & 79.6 & 0.13 \\
\hline
\end{tabular}

\section{Influence of the steel bar to the structure}

When the steel bar is not considered, the maximum axial tensile stress of upstream side and downstream side of the bottom board are $0.23 \mathrm{MPa}, 0.35 \mathrm{MPa}$ respectively, and the maximum 
opening of the vertical cracks is $0.79 \mathrm{~mm}$. The corresponding data are $1.32 \mathrm{MPa}, 1.67 \mathrm{MPa}$ and $0.15 \mathrm{~mm}$ respectively when considering the function of steel bar, and the maximum stress of steel bar is $91.5 \mathrm{MPa}$. We can see that the anti-crack function of steel bar is obvious.

\section{Influence of the vertical cracks to the structure}

When the depth of vertical cracks is $1.5 \mathrm{~m}$, the maximum axial tensile stress of upstream side and downstream side of the bottom board are 1.20MPa, 1.44MPa respectively, the maximum stress of steel bar is $79.6 \mathrm{MPa}$, and the maximum opening of the vertical cracks is $0.13 \mathrm{~mm}$. The corresponding data are $1.32 \mathrm{MPa}, 1.67 \mathrm{MPa}, 91.5 \mathrm{MPa}$ and $0.15 \mathrm{~mm}$ when the depth of vertical cracks is $2.5 \mathrm{~m}$. It indicated that when the vertical depth of cracks is bigger, the stress of concrete and steel bar is bigger, and the maximum opening of the cracks is bigger too.

\section{Conclusions}

The maximum axial stress of the bottom board with cracks is bigger than the values under the design condition, but the maximum stress of the concrete is only $1.67 \mathrm{MPa}$, and the stress of steel bar is not big, they are still within the allowed range. The structure is safe from the view of the stress.

Considering the defective parts of bottom surface and interlayer surface are likely to be connected with vertical cracks, seepage follow channel will be formed, and it will affect the long-term safe operation of the whole structure, it is suggested that cracks in the bottom board should be repaired, and the monitoring to the variation of the cracks should be strengthened.

\section{Acknowledgements}

This work was financially supported by the National Science Foundation of China (51409012) and the Basic Scientific Research Operation Cost of State-leveled Public Welfare Scientific Research Courtyard (CKSF2014054/CL, CKSF2015033/CL).

\section{References}

[1] Wan Diwen, Analysis of causes of cracks in sluice bottom of Xiajiang Hydro-junction based on finite element method, Journal of Nanchang Institute of Technology [J] (in Chinese), Vol.31, No.4, 2012(8), P. 54

[2] Hu Xufang, Liu Haitao, Causes Analysis and Prevention Measures on Concrete Crack in Some Sluice [J], Construction Technology [J] (in Chinese), Vol.42, No.12, 2013(6), P.71

[3] Zhang Yonghong, Feng Shuai, Qi Chun You, Cause Analysis and treatment on Concrete Crack of a River Sluice bottom Board, Science \& Technology Information [J] (in Chinese), 2010(17), P.350

[4] Zhu Bofang, the Finite Element Method Theory and Applications [M] (in Chinese), China Waterpower Press, 1998. 